\title{
Renal Pelvis Neoplasm
}

National Cancer Institute

\section{Source}

National Cancer Institute. Renal Pelvis Neoplasm. NCI Thesaurus. Code C8404.

A neoplasm involving the renal pelvis. 